\title{
Hubungan tipe kepribadian dengan prestasi akademik pada siswa SMA $X$
}

\author{
Muhammad Alkadri Anugrah, ${ }^{1}$ Dian Mediana $^{2}$
}

\begin{abstract}
ABSTRAK
LATAR BELAKANG

Proses pendidikan dipengaruhi oleh tiga unsur dasar, yaitu input, proses, dan luaran (output). Yang termasuk input adalah siswa dengan latar belakangnya. Proses adalah kegiatan pembelajaran yang berupa bentuk interaksi edukatif guru dengan siswa, mencakup pemberian dan pemahaman materi pelajaran. Luaran adalah hasil yang telah dicapai oleh siswa, meliputi kognitif, afektif dan psikomotorik. Setiap siswa mempunyai keunikan dan karakter masing-masing. Keunikan ini termasuk tipe kepribadian yang membuat siswa memiliki respon yang berbeda dalam memahami suatu pelajaran, baik dari segi sikap maupun gaya belajar yang menunjang keberhasilan belajarnya. Penelitian ini bertujuan mengetahui hubungan tipe kepribadian dengan prestasi akademik siswa.
\end{abstract}

\section{METODE}

Penelitian ini dilakukan menggunakan metode analitik observasional dengan pendekatan cross-sectional pada 378 siswa kelas XI dan XII IPA Sekolah Menengah Atas Negeri X. Data dikumpulkan dengan wawancara dan pengisian kuesioner Eysenck Personality Inventory (EPI) pada bulan September-November 2018. Analisis data menggunakan uji Chi-square dengan batas kemaknaan $\mathrm{p}<0.05$.

\section{HASIL}

Tipe kepribadian introvert $49.2 \%$, ekstrovert $50.8 \%$. Nilai eksakta tinggi $55.6 \%$, rendah $44.4 \%$. Nilai non-eksakta tinggi $63.8 \%$, rendah $36.2 \%$. Nilai rata-rata tinggi $52.9 \%$, rendah $47.1 \%$. Hubungan bermakna antara tipe kepribadian dengan nilai eksakta $(\mathrm{p}=0.000)$; dengan nilai noneksakta $(\mathrm{p}=0.000)$; dan dengan nilai rata-rata $(\mathrm{p}=0.000)$.

\section{KESIMPULAN}

Terdapat hubungan bermakna antara tipe kepribadian dengan prestasi akademik pada siswa SMA X.

Kata kunci: siswa, tipe kepribadian, prestasi akademik
${ }^{1}$ Program Studi Kedokteran, Fakultas Kedokteran Universitas Trisakti, Jakarta, Indonesia

2 Departemen Anatomi, Fakultas Kedokteran Universitas Trisakti, Jakarta, Indonesia

\section{Korespondensi:}

Dian Mediana

Departemen Anatomi, Fakultas

Kedokteran Universitas Trisakti, Jakarta, Indonesia

Jalan Kyai Tapa (Kampus B)

Usakti, Grogol, Indonesia 11440

Email:

dianmediana@trisakti.ac.id

J Biomedika Kesehat 2021;4(4):142147

DOI: 10.18051/JBiomedKes.2021. v4.142-147

pISSN: 2621-539X / eISSN: 2621-5470

Artikel akses terbuka (open access) ini didistribusikan di bawah lisensi Creative Commons Attribution 4.0 International (CC-BY 4.0) 


\section{ABSTRACT}

\section{Relationship between personality type and academic achievement in senior high school $X$ students}

\section{BACKGROUND}

The education process is affected by three basic elements, namely input, process, and output. Included in the input were students with backgrounds. The process was a learning activity in the form of teacher-student educative interaction, including giving and understanding subject material. Output was the result that has been achieved by students, including cognitive, affective and psychomotor. Every student has their own uniqueness and character. This uniqueness included personality types that make students have different responses in understanding a lesson, both in terms of attitudes and learning styles that support learning success. This study aims to determine the relationship between personality type and student academic achievement.

\section{METHODS}

This study was conducted using an observational analytic method with a cross-sectional approach on 378 students of class XI and XII IPA, at Senior High School X. Data were collected by interview and filling out the Eysenck Personality Inventory (EPI) questionnaire in September-November 2018. Data analysis used the Chi-square test with the limit of significance was $\mathrm{p}<0.05$.

\section{RESULTS}

Personality type: introvert $49.2 \%$, extrovert $50.8 \%$. Academic achievement: high exact scores $55.6 \%$, low exact scores $44.4 \%$, high non-exact scores $63.8 \%$, low non-exact scores $36.2 \%$, high average (exact and non-exact) scores $52.9 \%$, low average scores $47.1 \%$. There was a significant relationship between personality type and exact scores, non-exact scores, and average scores $(\mathrm{p}=0.000 ; \mathrm{p}=0.000 ; \mathrm{p}=0.000)$.

\section{CONCLUSION}

There was a significant relationship between personality type and academic achievement in high school students.

Keywords: students, personality type, academic achievement

\section{PENDAHULUAN}

Proses pendidikan dipengaruhi tiga unsur dasar, yaitu input, proses, dan luaran (output). Yang disebut input adalah siswa dengan latar belakangnya. Proses adalah kegiatan pembelajaran yang berupa bentuk interaksi edukatif guru dengan siswa, mencakup pemberian dan pemahaman materi pelajaran. Output adalah hasil yang telah dicapai oleh siswa, meliputi kognitif, afektif, dan psikomotor. Di antara ketiga unsur tersebut, yang nantinya akan menentukan baik tidaknya kemampuan dan hasil belajar siswa adalah proses pembelajaran. ${ }^{(1)}$ Siswa SMA merupakan individu yang memiliki kemampuan untuk melaksanakan tugasnya belajar secara optimal. Agar mencapai suatu prestasi belajar yang baik, siswa diharapkan dapat melakukan tugas belajarnya secara tepat. (2) Salah satu upaya untuk meningkatkan mutu pendidikan adalah dengan meningkatkan kualitas belajarsehingga prestasibelajarpunikutmeningkat. (3) Sehubungan dengan prestasi belajar tersebut, diharapkan kemampuan lulusan yang utuh yang mencakup kemampuan kognitif, psikomotor dan afektif atau perilaku. ${ }^{(4)}$ Setiap siswa mempunyai keunikan dan karakter masing-masing. Keunikan ini termasuk tipe kepribadian yang membuat siswa memiliki respon yang berbeda dalam memahami suatu pelajaran, baik dari segi sikap maupun gaya belajar yang menunjang keberhasilan belajarnya.

Siswa yang memiliki kepribadian ekstrovert lebih menyukai belajar berkelompok dan diskusi, sedangkan siswa dengan kepribadian introvert lebih menyukai belajar secara individu. Menurut penelitian yang dilakukan oleh Putra IG, et al bahwa individu dengan tipe kepribadian introvert $(43.5 \%)$ lebih sedikit dibandingkan dengan tipe kepribadian ekstrovert $(56.5 \%){ }^{(5)}$ Menurut penelitian Ghazi SR, et al bahwa secara keseluruhan tidak ada hubungan signifikan yang ditemukan antara ciri kepribadian siswa dengan prestasi akademik. ${ }^{(6)}$ Berbeda dengan penelitian lainnya yang menyatakan bahwa terdapat hubungan signifikan antara prestasi akademik dan sifat kepribadian, dianggap sebagai faktor penting yang mempengaruhi pembelajaran dan pencapaian mahasiswa. ${ }^{(7)}$ Adanya perbedaan hasil dari penelitian terdahulu inilah yang membuat peneliti tertarik untuk meneliti lebih lanjut mengenai hubungan tipe kepribadian (introvert dan ekstrovert) dengan prestasi akademik pada siswa SMA.

\section{METODE}

Penelitian ini bersifat deskriptif analitik 
dengan pendekatan cross-sectional. Dilakukan di Sekolah Menengah Atas Negeri X pada bulan September - November 2018 dengan jumlah sampel 378 orang siswa, diambil menggunakan teknik cluster random sampling pada 10 kelas XI IPA dan 10 kelas XII IPA. Sebelumnya responden sudah menandatangani informed consent. Kriteria inklusi pada penelitian ini adalah siswa aktif kelas XI IPA dan XII IPA di SMA Negeri X. Variabel bebas dari penelitian ini adalah tipe kepribadian dan variabel tergantungnya adalah prestasi akademik. Data primer diperoleh dari wawancara dan pengisian kuesioner Eysenck Personality Inventory (EPI). Data sekunder diperoleh dari bagian Tata Usaha sekolah untuk mengetahui jumlah seluruh siswa dan rata-rata nilai raport siswa. Nilai raport dibagi menjadi tiga kategori: 1) nilai eksakta, terdiri dari mata pelajaran Matematika, Biologi, Fisika dan Kimia; 2) nilai non eksakta, terdiri dari mata pelajaran Pendidikan Agama Islam (PAI), Pendidikan Kewarganegaraan $(\mathrm{PKn})$, Bahasa Indonesia, Sejarah Indonesia, Seni Budaya, Pendidikan Jasmani Olahraga dan Kesehatan (PJOK) dan Pendidikan Kewirausahaan (PKU); dan 3) nilai rerata eksakta dan non eksakta. Nilainya dibagi menjadi dua kategori, yaitu tinggi dan rendah berdasarkan mean nilai raport siswa.

Analisis data yang dilakukan adalah univariat dengan memaparkan hasil distribusi frekuensi dan persentase dari setiap variabel. Analisis bivariat dilakukan untuk melihat hubungan antara variabel bebas dengan variabel terikat menggunakan uji Chi-square dengan tingkat kemaknaan adalah $<0.05$. Penelitian ini dilaksanakan setelah memperoleh ethical clearance dari Komisi Etik Penelitian Fakultas Kedokteran Universitas Trisakti dengan Nomor 12/KER-FK/VIII/2018.

\section{HASIL}

Penelitian ini dilakukan pada siswa kelas XI IPA dan XII IPA di SMA Negeri X pada bulan September-Oktober 2018. Berdasarkan hasil wawancara terhadap 378 siswa, didapatkan bahwa sebagian siswa memiliki tipe kepribadian ekstrovert. Sedangkan untuk prestasi belajar yang diperoleh dari buku raport, diketahui bahwa sebagian besar siswa memiliki nilai tinggi, baik dalam kategori eksakta, non-eksakta dan nilai rata-rata eksakta dan non-eksakta.
Tabel 1. Distribusi frekuensi tipe kepribadian, nilai eksakta, non-eksakta, dan nilai rata-rata

\begin{tabular}{lll}
\hline Karateristik Responden & n & \% \\
\hline Tipe Kepribadian & & \\
Introvert & 186 & 49.2 \\
Ekstrovert & 192 & 50.8 \\
Prestasi Akademik & & \\
Nilai Eksakta & & \\
Tinggi & 210 & 55.6 \\
Rendah & 168 & 44.4 \\
Nilai Non-Eksakta & & \\
Tinggi & 241 & 63.8 \\
Rendah & 137 & 36.2 \\
Nilai Rata-Rata & & \\
Tinggi & 200 & 52.9 \\
Rendah & 178 & 47.1 \\
\hline Keterangan: & jumlah; &
\end{tabular}

Keterangan: $\mathrm{n}=$ jumlah; $\%=$ persentase

Dilakukan uji statistik Chi-square pada hubungan tipe kepribadian dengan prestasi akademik, didapatkan nilai probabilitas $\mathrm{p}=0.000$ untuk nilai eksakta, $\mathrm{p}=0.000$ untuk nilai noneksakta, dan $p=0.000$ untuk nilai rata-rata eksakta dan non eksakta. Dari hasil ini dapat dilihat bahwa nilai $\mathrm{p}<0.05$, sehingga dapat disimpulkan terdapat hubungan bermakna antara tipe kepribadian dengan prestasi akademik pada siswa SMA.

\section{PEMBAHASAN}

Dari 378 siswa didapatkan lebih dari separuh siswa memiliki tipe kepribadian ektrovert (50.8\%). Tipe kepribadian adalah sikap khas individu dalam berperilaku, merupakan semua yang mengarah ke luar atau ke dalam individu itu sendiri, sehingga bisa dibedakan dengan individu lain. ${ }^{(8)}$ Tipe kepribadian dikelompokkan menjadi tiga jenis yaitu: ekstrovert, introvert, dan ambivert. Namun, pada dasarnya tipe kepribadian utama setiap individu terdiri dari dua yaitu ekstrovert dan introvert. Menurut teori yang dikemukakan oleh Suryabrata, orang yang ekstrovert sebagian besar dipengaruhi oleh lingkungan, baik lingkungan sosial maupun non-sosial. ${ }^{(9)}$ Lingkungan sekolah merupakan salah satu aspek yang berperan penting dalam pembentukan kepribadian seseorang, iklim emosional kelas yang sehat serta sikap dan perilaku guru yang baik akan memberikan dampak positif terhadap kepribadian siswanya. Sekolah Menengah Atas (SMA) Negeri X merupakan salah satu sekolah unggulan di daerahnya yang dikenal dengan suasana lingkungan sekolah yang nyaman. Hal ini dapat mendukung terbentuknya kepribadian siswa ekstrovert yang diaplikasikan 
Tabel 2. Hubungan tipe kepribadian dengan prestasi nilai eksakta, non-eksakta, dan rata-rata

\begin{tabular}{|c|c|c|c|}
\hline & \multicolumn{2}{|c|}{ Tipe Kepribadian } & \multirow[b]{2}{*}{ Nilai $p$} \\
\hline & $\begin{array}{c}\text { Introvert } \\
\text { n (\%) }\end{array}$ & $\begin{array}{c}\text { Ekstrovert } \\
\text { n (\%) }\end{array}$ & \\
\hline \multicolumn{4}{|c|}{ Nilai eksakta } \\
\hline Tinggi & $130(69.9 \%)$ & $80(41.7 \%)$ & \multirow[t]{2}{*}{$0.000^{\#}$} \\
\hline Rendah & $56(30.1 \%)$ & $112(58.3 \%)$ & \\
\hline \multicolumn{4}{|c|}{ Non-eksakta } \\
\hline Tinggi & $138(74.2 \%)$ & $103(53.6 \%)$ & \multirow{2}{*}{$0.000^{\#}$} \\
\hline Rendah & $48(25.8 \%)$ & $89(46.4 \%)$ & \\
\hline \multicolumn{4}{|c|}{ Rata-rata } \\
\hline Tinggi & $126(67.7 \%)$ & $74(38.5 \%)$ & \multirow{2}{*}{$0.000^{\#}$} \\
\hline Rendah & $60(32.3 \%)$ & $118(61.5 \%)$ & \\
\hline
\end{tabular}

Keterangan: $\mathrm{n}=$ jumlah; \%persentase; ${ }^{*}=\mathrm{Uji}$ statistik Chi-square

dengan mudah bergaul, hubungan dengan orang lain yang lancar, dan terbuka dengan lingkungan. (10)

Pada variabel tergantung, yaitu prestasi belajar diperoleh dari nilai rapor siswa yang digolongkan menjadi eksakta, non-eksata dan rata-rata. Pada hasil penelitian didapatkan lebih dari setengah responden memiliki prestasi belajar tinggi (eksakta 55.6\%, non-eksakta 63.8\%, dan rata-rata $52.9 \%$ ). Nilai akademik yang tinggi pada siswa di SMA Negeri $X$ juga beralasan karena memang sekolah ini termasuk sekolah yang menerima siswa lulusan Sekolah Menengah Pertama (SMP) dengan nilai yang tinggi juga. Ditinjau dari teori yang mempengaruhi prestasi belajar, tipe kepribadian merupakan salah satu dari faktor internal. Faktor internal lainnya berupa fisik dan psikologi yang berupa minat, intelegensi, bakat, tingkat kecerdasan, kemandirian, dan motivasi. Faktor eksternal mencakup lingkungan (alam dan sosial) dan instrumental (kurikulum, program, sarana, dan metode pembelajaran). ${ }^{(11)}$ Menurut Tastan SB, et al arahan dan motivasi guru juga sangat mempengaruhi keberhasilan akademik siswa. ${ }^{(12)}$

Berdasarkan hasil analisis bivariat dengan uji statistic Chi-square diperoleh bahwa terdapat hubungan signifikan antara tipe kepribadian dengan prestasi akademik siswa $(\mathrm{p}<0.05)$. Hal ini sejalan dengan penelitian yang dilakukan oleh Karatas $\mathrm{H}$ yang mengungkapkan bahwa terdapat hubungan signifikan antara prestasi akademik dengan sifat kepribadian, dengan kata lain sifat kepribadian dianggap sebagai faktor penting yang mempengaruhi proses pembelajaran dan pencapaian hasil belajar siswa. ${ }^{(7)}$ Menurut Bergold S, upaya teoritis dan praktis di masa depan untuk mengupayakan prestasi akademik harus lebih banyak mengintegrasikan hubungan antara kepribadian dan prestasi akademik. (13) Hasil penelitian ini juga sejalan dengan penelitian yang dilakukan oleh Chinelo OE, et al yang mengungkapkan bahwa terdapat perbedaan signifikan antara prestasi ratarata belajar matematika siswa dengan dua kelompok kepribadian yang mendukung proses pembelajaran tersebut. Pencapaian prestasi pada siswa dengan kepribadian ekstrovert sedikit lebih tinggi dibandingkan dengan siswa introvert. ${ }^{(14)}$ Penelitian oleh Forouzan N juga mengungkapkan bahwa kepribadian memiliki dampak signifikan dengan kemampuan siswa membaca metastrategi Self Directed Learning (SDL), di mana tipe kepribadian introvert mempunyai kemampuan lebih tinggi jika dibandingkan dengan ekstrovert. (15)

Penelitian lainnya menggunakan sebuah post-test yang diberikan kepada siswa, hasilnya menunjukkan bahwa siswa introvert mendapatkan nilai lebih tinggi dan memiliki kemampuan membaca yang lebih baik dibandingkan dengan siswa ekstrovert. ${ }^{(16)} \mathrm{Hal}$ ini didasarkan pada teori yang mengemukakan bahwa individu dengan tipe kepribadian introvert cenderung tertarik pada ide-ide, abstraksi-abstraksi, masalah filsafat, diskusi, spekulasi dan pengetahuan. Sedangkan kepribadian ekstrovert lebih tertarik untuk melakukan berbagai hal daripada memikirkan hal-hal tersebut dan cenderung tidak sabar dengan perbuatan teori-teori. ${ }^{(17)} \mathrm{Hal}$ ini dapat dikaitkan 
dengan teori perbedaan fungsi otak kanan dan otak kiri. Beberapa pakar mengatakan bahwa otak kiri merupakan pusat Intelligence Quotient (IQ). Pendidikan formal di sekolah lebih banyak menstimulasi kemampuan otak kiri. Dampak dari individu yang dominan menggunakan otak kirinya adalah pandai melakukan analisa dan proses pemikiran logis, namun kurang pandai dalam hubungan sosial. Sedangkan individu yang kerja mengoptimalkan otak kanannya akan menjadi pandai bergaul, namun mengalami kesulitan dalam belajar hal-hal yang teknis. ${ }^{(18)}$

Namun terdapat hasil yang berbeda dari penelitian yang dilakukan oleh Ghazi SR, et al bahwa tidak terdapat hubungan signifikan yang ditemukan pada ciri kepribadian siswa dengan prestasi akademik. ${ }^{(6)}$ Perbedaan hasil penelitian ini dikarenakan penggolongan tipe kepribadian yang berbeda. Dalam penelitiannya, tipe kepribadian digolongkan menjadi extroversion, neuroticism dan openness to experience, sedangkan pada penelitian ini digolongkan menjadi ekstrovert dan introvert. Studi lain yang dilakukan oleh Prayitno, et al juga didapatkan bahwa tidak terdapat perbedaan bermakna antara tipe kepribadian ektrovert dan introvert terhadap speaking skill mahasiswa ${ }^{(19)}$ Hal ini karena perbedaan analisis data. Pada penelitian Prayitno, et al analisis data menggunakan uji sample t-test independent, sedangkan penelitian ini menggunakan uji Chisquare karena variabel bebas dan terikatnya sudah dikategorikan terlebih dahulu.

Masing-masing ciri kepribadian berkorelasi dengan Indeks Prestasi Akademik (IPK). Kesadaran berperan sebagai kunci motivasi untuk berprestasi, yang sebelumnya dibuktikan dalam banyak penelitian. Kedua sifat tersebut juga ditemukan sebagai prediktor IPK yang signifikan. ${ }^{(20)}$ Hasil penelitian Lechner CM, et al menyatakan sifat kepribadian adalah yang paling relevan dengan pencapaian prestasi akademik pada siswa dengan sosioekonomi yang lebih tinggi. ${ }^{(21)}$ Penggolongan tipe kepribadian dapat bermanfaat untuk menghargai perbedaan tiap individu dan sebagai penunjang keberhasilannya. Dari sini diharapkan agar tiap individu mampu memecahkan masalah kehidupannya, didasari oleh nilai sekaligus dapat membantu membangun karakternya. ${ }^{(11)}$ Para pengajar harus mendorong siswanya untuk mendapatkan stabilitas, motivasi dan ketekunan, bersama dengan toleransi terhadap frustasi. Jika strategi pengajaran diberikan sesuai dengan ciri kepribadian siswa, prestasi akademik akan meningkat, karena proses pembelajaran dapat ditingkatkan. ${ }^{(20)}$ Dengan kemajuan teknologi di bidang kedokteran neurologi, pada tahun 2018 dikembangkan suatu alat untuk mendiagnosis tipe kepribadian yang disebut neuroscience network personality menggunakan magnetic resonace imaging (MRI) fungsional. Alat ini dapat digunakan pada studi perbedaan kepribadian individu dan mengeksplorasi potensinya, baik dalam bidang akademik maupun non akademik. ${ }^{(22)}$

Penelitian ini memiliki beberapa keterbatasan, yaitu pertama hanya membagi dua tipe kepribadian yaitu ekstrovert dan introvert, sehingga untuk melihat pengaruh kepribadian terhadap prestasi belajar belum secara spesifik. Kedua, prestasi belajar merupakan hasil dari proses belajar yang dipengaruhi oleh banyak faktor.

\section{KESIMPULAN}

Terdapat hubungan signifikan antara tipe kepribadian dengan prestasi belajar eksakta $(\mathrm{p}=0.000)$, non-eksakta $(\mathrm{p}=0.000)$, dan rata-rata $(\mathrm{p}=0.000)$. Disarankan untuk diadakan penelitian lebih lanjut dengan populasi lebih luas dengan meneliti lebih dari satu sekolah, hal ini juga dapat dilakukan untuk mengetahui perbandingan hasil penelitian antara satu sekolah dengan sekolah lainnya. Meneliti faktor lain dan tipe kepribadian yang lebih spesifik, sehingga dapat mendeskripsikan hubungan tipe kepribadian dengan prestasi belajar secara lebih jelas.

\section{UCAPAN TERIMA KASIH}

Pihak SMA Negeri 3 Padang dan Fakultas Kedokteran Universitas Trisakti

\section{KONFLIK KEPENTINGAN}

Peneliti tidak memiliki konflik kepentingan terhadap hasil penelitian ini.

\section{REFERENSI}

1. Rijal S, Bachtiar S. Hubungan antara sikap, kemandirian belajar, dan gaya belajar dengan hasil belajar kognitif siswa. Jurnal Bioedukatika. 2015;(3)2:15-20. doi: 10.26555/bioedukatika. v3i2.4149

2. Utaminingsih S, Setyabudi I. Tipe kepribadian 
dan prokrastinasi akademik pada siswa SMA $\mathrm{X}$ Tangerang. Jurnal Psikologi [Internet]. 2012;(10)1:48-57. Available from: https://ejurnal. esaunggul.ac.id/index.php/psiko/article/view/1476

3. Damayanti A, Pratitis NT. Gaya belajar ditinjau dari tipe kepribadian dan jenis kelamin. Persona: Jurnal Psikologi Indonesia. 2012;(1)2:88-98. doi: 10.30996/persona.v1i2.333

4. Daud F. Pengaruh kecerdasan emosional (EQ) dan motivasi belajar terhadap hasil belajar biologi siswa SMA 3 Negeri Kota Palopo. Jurnal Pendidikan dan Pembelajaran [Internet]. 2012;(19)2:243-255. Available from: http://journal.um.ac.id/index.php/ pendidikan-dan-pembelajaran/article/view/3475

5. Putra IG, Aryani LN. Hubungan antara tipe kepribadian introvert dan ekstrovert dengan kejadian stres pada ko-asisten angkatan tahun 2011 Fakultas Kedokteran Universitas Udayana. E-Jurnal Medika Udayana [Internet]. 2015;4(4):111. Available from: https://ojs.unud.ac.id/index. php/eum/article/view/15086

6. Ghazi SR, Syahzada G, Ullah S. Relationship between students' personality traits and their academic achievement in Khyber Pakhtunkhwa, Pakistan. Journal of Educational and Social Research [Internet]. 2013;(3)2:437-44. Available from: https://www.mcser.org/journal/index.php/ jesr/article/view/269

7. Karatas H. Correlation among academic procrastination, personality traits, and academic achievement anthropologist. The Anthropologist. 2015;20:243-55

8. Haryanto D, Nur IM. Sistem pakar tes kepribadian ekstrovert dan introvert dengan metode forward chaining. Jurnal Teknik Informatika [Internet]. 2017;5:2:11-20. Available from: http://jurnal. stmik-dci.ac.id/index.php/jutekin/article/view/138

9. Suryabrata S. Psikologi kepribadian. Jakarta: PT Raja Grafindo Persada; 2011

10. Syamsu Y, Juntika N. Teori kepribadian. Jakarta: Badan penerbit PT Remaja Rosdakarya; 2012

11. Slameto. Belajar dan faktor-faktor yang mempengaruhinya. Jakarta: Rineka Cipta; 2013

12. Tastan SB, Davoudi SMM, Masalimova AR, et al. The impacts of teacher's efficacy and motivation on student's academic achievement in science education among secondary and high school students. EURASIA Journal of Mathematics, Science and Technology Education. 2018; 14(6): 2353-66. doi: 10.29333/ejmste/89579

13. Bergold S, Steinmayr R. Personality and intelligence interact in the prediction of academic achievement. J Intell. 2018;6(2):27._doi: 10.3390/ jintelligence 6020027

14. Chinelo OE, Fransisca ON, Blesssing MA. Enhancing mathematics achievement of introverted and extroverted secondary school students through the use of advance organizers. Journal of Educational Research and Review: 2016;4(3):27-32

15. Forouzan N, TabriziARN. The effect of self directed learning strategies on introvert vs. Extrovert iranian efl learners' reading comprehension. International Journal of Language Learning and Applied Linguistics World (IJLLALW): 2015;9(2)

16. Rekabdar S, Behrouzi P, Hakhverdian A. The effect of using metacognitive strategies on reading achievement of iranian intermediate extroverted vs. introverted learners. International Journal of Educational Investigations. 2015;2:1
17. Ekayana SD, Hermanto D, Affaf M. Profil Berpikir Kreatif Siswa SMP dalam Menyelesaikan Masalah Matematika Kontekstual Berdasarkan Perbedaan Tipe Kepribadian Introvert dan Ekstrovert. JEMS. 2020;8(2):165-71 doi: 10.25273/jems.v8i2.7605 165

18. Mulders P, Llera A, Tendolkar I, et al. Personality profiles are associated with functional brain networks related to cognition and emotion. Sci Rep. 2018;8:13874. doi: 10.1038/s41598-01832248-x

19. Prayitno, Siswoto H, Sylene M. Hubungan antara kepribadian introvert dan ekstrovert dengan speaking skill mahasiswa prodi D III keperawatan. Jurnal Unmuh Jember; 2018;14:1858-4063

20. Kusnierz C, Rogowska AM, Pavlova I. Examining gender differences, personality traits, academic performance, and motivation in Ukrainian and Polish students of physical education: a crosscultural study. Int J Environ Res Public Health. 2020;17(16):5729. doi: 10.3390/ijerph17165729

21. Lechner CM, Bender J, Brandt ND, et al. Two forms of social inequality in students' socio-emotional skills: Do the levels of big five personality traits and their associations with academic achievement depend on parental socioeconomic status? Front Psychol. 2021;12:679438. doi: 10.3389/ fpsyg.2021.679438

22. Markett S, Montag C, Reuter M. Network neuroscience and personality. Personal Neurosci. 2018;1:e14. doi: 10.1017/pen.2018.12 